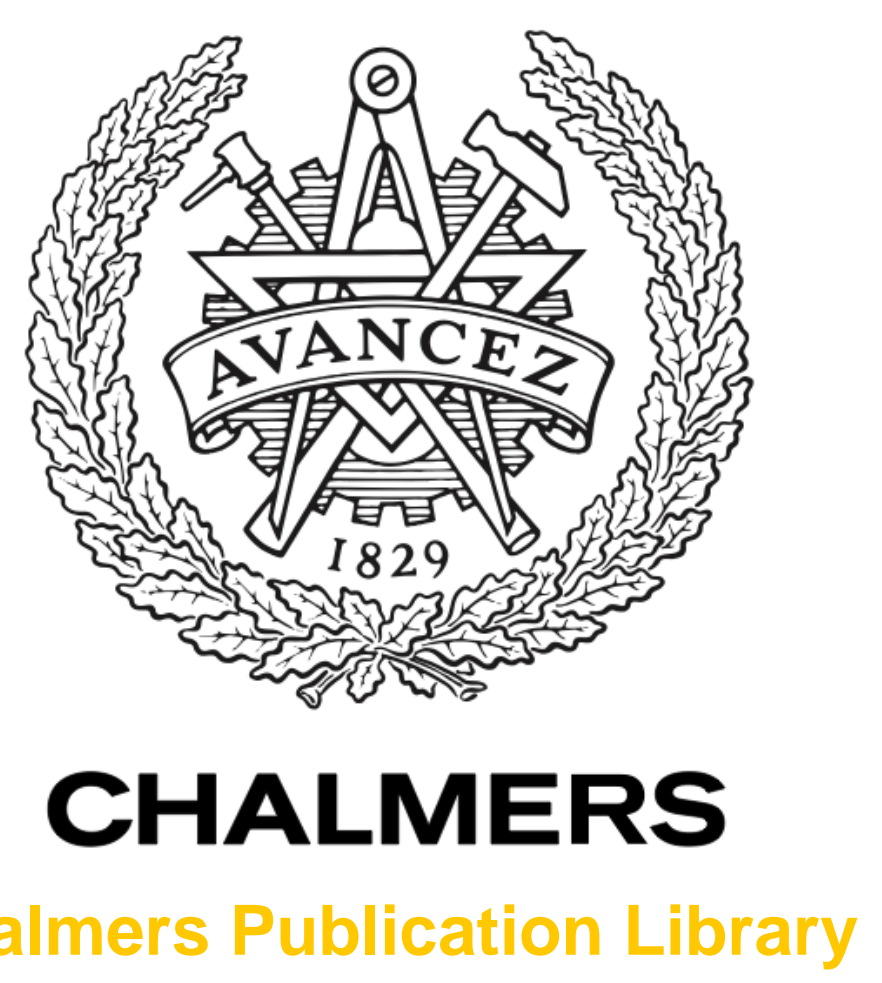

Chalmers Publication Library

\title{
A methodology for estimating risks associated with landslides of contaminated soil into rivers
}

This document has been downloaded from Chalmers Publication Library (CPL). It is the author's version of a work that was accepted for publication in:

Science of the Total Environment (ISSN: 0048-9697)

Citation for the published paper:

Goransson, G. ; Norrman, J. ; Larson, M. et al. (2014) "A methodology for estimating risks associated with landslides of contaminated soil into rivers". Science of the Total

Environment, vol. 472 pp. 481-495.

http://dx.doi.org/10.1016/j.scitotenv.2013.11.013

Downloaded from: http://publications.lib.chalmers.se/publication/196171

Notice: Changes introduced as a result of publishing processes such as copy-editing and formatting may not be reflected in this document. For a definitive version of this work, please refer to the published source. Please note that access to the published version might require a subscription. 


\section{A methodology for estimating risks associated with landslides of contaminated soil into rivers}

Gunnel Göransson ${ }^{1,2}$, Jenny Norrman ${ }^{3,1}$, Magnus Larson ${ }^{2}$, Claes Alén ${ }^{3}$ and Lars Rosén ${ }^{3}$

${ }^{1}$ Department of Land use Planning and Climate Adaptation, Swedish Geotechnical Institute, SE-412

96, Gothenburg, Sweden. E-mail: gunnel.goransson@ @swedgeo.se, phone: +46317786567

(corresponding author)

${ }^{2}$ Department of Water Resources Engineering, Lund University, SE-221 00 Lund, Sweden. E-mail: magnus.larson@tvrl.lth.se

${ }^{3}$ Department of Civil and Environmental Engineering, Chalmers University of Technology, SE-412

96, Gothenburg, Sweden. E-mails: jenny.norrman@chalmers.se; claes.alen@chalmers.se;

lars.rosen@chalmers.se 


\begin{abstract}
Urban areas adjacent to surface water are exposed to soil movements such as erosion and slope failures (landslides). A landslide is a potential mechanism for mobilisation and spreading of pollutants. This mechanism is in general not included in environmental risk assessments for contaminated sites, and the consequences associated with contamination in the soil are typically not considered in landslide risk assessments. This study suggests a methodology to estimate the environmental risks associated with landslides in contaminated sites adjacent to rivers. The methodology is probabilistic and allows for datasets with large uncertainties and the use of expert judgements, providing quantitative estimates of probabilities for defined failures. The approach is illustrated by a case study along the river Göta Älv, Sweden, where failures are defined and probabilities for those failures are estimated. Failures are defined from a pollution perspective and in terms of exceeding environmental quality standards (EQS) and acceptable contaminant loads. Models are then suggested to estimate probabilities of these failures. A landslide analysis is carried out to assess landslide probabilities based on data from a recent landslide risk classification study along the river Göta Älv. The suggested methodology is meant to be a supplement to either landslide risk assessment (LRA) or environmental risk assessment (ERA), providing quantitative estimates of the risks associated with landslide in contaminated sites. The proposed methodology can also act as a basis for communication and discussion, thereby contributing to intersectoral management solutions. From the case study it was found that the defined failures are governed primarily by the probability of a landslide occurring. The overall probabilities for failure are low; however, if a landslide occurs the probabilities of exceeding EQS are high and the probability of having at least a $10 \%$ increase in the contamination load within one year is also high.
\end{abstract}

Keywords: Contaminated sites; environmental risk assessment; landslide risk assessment; Monte Carlo simulation; pollution transport, water quality

\title{
1. Introduction
}

Contaminated land subject to landslides poses a risk for mobilisation and spreading of contaminants into rivers, as has previously been highlighted in papers by Göransson et al. (2009; 2012). The first paper identified the combination of landslides and contaminated land as a multi-risk and suggested a conceptual model for the governing processes. The second paper applied a one-dimensional advectiondispersion equation for the description of possible sediment, and subsequent contaminant transport for the instantaneous release of contaminants from landslides.

Landslides are often natural geomorphological processes resulting from nature striving towards equilibrium and they are important for the rejuvenation of the ecology (Geertsema et al., 2009). In pristine environments such events release nutritious sediments to the surroundings and are 
mechanisms for maintaining aquatic and terrestrial biodiversity and heterogeneity (Attiwill, 1994; Geertsema and Pojar, 2007). A landslide can cause an instantaneous increase in turbidity, which influences light suppression, and it may induce a sudden change in redox and $\mathrm{pH}$, or cause instantaneous fish kill because of the physical chock. Such impacts only remain for a limited period of time and most natural systems are resilient to these events and have capacity for recovery (Folke et al., 2004; Holling, 1973; Waples et al., 2009).

However, when a natural system is no longer pristine but transformed into an anthropogenic system, a landslide may not only be triggered by human activities but the consequences may also increase because anthropogenic systems are often contaminated to various extents. For example, release of excessive nutrients from agriculture or bacteria and viruses from pasture lands into rivers from landslides (Ohlson and Serveiss, 2007)and landslides that involve contaminated material can transport pollutants from land to rivers. This can occur either directly due to the sliding masses or indirectly by flooding and bank erosion of polluted areas as a consequence of damming and landslide generated impulse waves (Göransson et al., 2012; Göransson et al., 2009; Bonnard et al., 2004). A landslide that involves the release and transport of contaminating substances may also trigger a shift into an ecosystem of less resilience (Folke et al., 2004; Holling, 1973; Walker et al., 2009).

Although urban areas and industrial sites are commonly located adjacent to surface water, very few studies have paid attention to the risk for mobilisation and spreading of pollutants to surface waters due to landslides (Göransson et al., 2012). Existing methods for environmental risk assessment (ERA) and risk management at a river basin scale do not provide information on the possible environmental impact from landslides or other types of mass movement. Yet fine sediment, sediment transport, as well as contaminant transport and mobilisation due to groundwater flow and the release of contaminated sediments from rivers and floodplains due to flooding are typically mentioned in ERA (see for example Landis, 2004; Marcus et al., 2001; US EPA, 2012; and European projects like RISKBASE, MODELKEY, AguaTerra; e.g., Diaz-Cruz et al., 2007; Finkel et al., 2010; or visit www.riskbase.info, www.modelkey.org). In addition, existing methods for landslide risk assessments (LRA) do not account for the pollution potential although the environment is often included as an 
element at risk (see for example Li et al., 2010; Ohlson and Serveiss, 2007; Serveiss and Ohlson, 2007; Poli and Sterlacchini, 2007; Sterlacchini et al., 2007; or visit the European project SafeLand at www.safeland-fp7.eu).

The risk of landslides in polluted areas is increasingly relevant since there are indications that: (1) landslide frequencies may increase in areas with increasing precipitation or temperature (although the uncertainties still remain high) and (2) there is a possible increase in anthropogenic landslides due to unsustainable development (Borgatti and Soldati, 2010; Crozier, 2010; Jakob and Lambert, 2009; Kuriakose et al., 2009; Klimeš and Novotný, 2011; Larsen, 2008; Listo and Vieira, 2012; Ren et al., 2011). It is therefore relevant to develop an approach for assessing the risks associated with contaminant mobilisation from landslides in order to include this issue into risk models.

The main aim of this study is to propose a methodology for quantitative estimation of risks to water bodies from landslides involving contaminated land. Risk is here related to the probability of exceeding a defined failure criterion, whereby the consequences associated with the event of interest can not necessarily be quantified. The suggested methodology may be a useful complement to ERA at contaminated sites or in LRA, or provide important input in river basin management. The suggested methodology is illustrated through a case study.

\section{Conceptualisation}

The governing processes for the release and exposure of contaminants from landslides have been described in Göransson et al. (2009; 2012). Based on these two studies, the following conceptualisation of the contaminant release and exposure mechanisms is as follows:

A. An instantaneous exposure in the near field as the contaminated masses come into contact with the water because of the slide.

B. An instantaneous release of particle bound contaminants from the landslide deposit as it reaches the surface water and soil particles go into suspension. Particle bound contaminants 
are mobilised and further transported downstream (upstream transport is also possible) with the landslide-generated wave and the river flow. Exposure along the downstream transport pathway is possible as the contaminant pulse moves down the river.

C. An instantaneous release of dissolved substances from the landslide deposit as the contaminated masses reach the water column and are transported with the flow. Exposure along the downstream transport pathway with the water flow is possible.

D. More or less instantaneous exposure in the accumulation area (far field) when the released substances settle.

E. A long-term exposure in the near field from the contaminated landslide deposits. Releases of both particle and dissolved contaminants from the runout are expected as a consequence of erosion and diffusion. Such releases can continue for a very long time (years, decades), if dredging does not take place. Possible long-term exposure along the pathway depends, for example, on dispersion processes.

F. A long-term exposure in the far field is expected as contaminants accumulate from the event.

Given the conceptualisation above, potential consequences can be related to three impact zones: I) the near field, II) along the transport pathway, and III) the far field accumulation area; see Fig. 1 and Table 1. Zone II may be limited when the slope runs out directly into a lake or the sea.

\section{Suggested risk estimation methodology}

The common definition of risk includes the combination of the probability of an event and the undesirable consequences of such an event. Typically, a risk assessment starts with hazard identification. Here, the hazard is already defined as the combination of slope instability and land contamination; thus, the identification step is not included in the suggested methodology but is described in Göransson et al. (2009).

There are no studies on environmental consequences for the impact zones described above and the consequences must therefore be defined from something other than field measurements or 
experiments, for example from a policy or acceptance aspect. The suggestion made here is to use environmental quality standards (EQS) since they indirectly tell something about the risk because they consider effects (e.g., biological) and responses (e.g., the amount affected). Accordingly, the methodology does not describe the consequences but is based on the identification of failures. These failures are defined in terms of exceeding relevant guideline or threshold values related to contaminant concentration or maximum additional contaminant load to the system. Failure criteria are defined for each of the impact zones (I - III) and a decision is then made on the probability models to use for the calculation of these failures. For each case, one needs to investigate data availability, find expert judgements when data are lacking and consider the uncertainties in the data and the judgements. The risk is then estimated by calculating the probability of failure in each impact zone. The following working approach is suggested and further explained under the coming sections:

1. Identify initial conditions of the surface water system.

2. Define failure for impact zones I - III.

3. Decide models to calculate probabilities of failure.

4. Set parameter values and parameter uncertainties.

5. Compute the probability of failure $\left(P_{f}\right)$ for all identified failures.

6. Perform a sensitivity analysis.

The work is preferably carried out in an iterative mode, since the level of complexity of the analysis depends on what the result will be used for and on the available resources in the form of data, knowledge, and funding.

\subsection{Identifying initial conditions of water system (step 1)}

The condition of the surface water is important for what might be considered an acceptable risk; the consequences of a pollution release to a water system will depend on its environmental status (e.g., water quality, impacts from point and non-point sources), sensitivity and vulnerability (e.g., species susceptibility to contamination, vulnerable species), and usage, now and in the future (e.g., fishing, 
nurseries for important species, bathing, fresh water supply). The consequences of any additional pollution load will depend on these aspects. As an example, species in a system with good water and sediment quality can be sensitive to very small changes in concentrations, i.e., they have less tolerance to toxicants (Blanck, 2002) and the level of acceptance for an additional load is probably low.

\subsection{Defining failure (step 2)}

With respect to ERA and LRA, defining failure best corresponds to the assessment of endpoints in traditional ERA methods (see for example Ohlson and Serveiss, 2007; Suter et al., 2004) or to a combination of assessing the vulnerability and the elements at risk in LRA methods (see for example AGS, 2000; Li et al., 2010).

In this study, failure is considered from a pollution perspective and defined in terms of environmental quality standards (EQS) and levels of acceptance. According to the Environment Agency in UK, EQS aim to 'protect wildlife and nature', and 'control risks to the quality of water' (The UK Environment Agency, 2013). The EQS may be generic or site-specific based on the conditions in the water system, whereas levels of acceptance would be site-specific considerations. The motivations for defining failure in each of the impact zones are:

- Failure, impact zone I: The concentration in soil on land should be related to the possible concentration in the sediments (as landslide runout deposit). If the contaminated soil constitutes a high risk then it will certainly constitute high risk also if it ends up as sediment in the water. In soil, concentration decreases in general with depth but depends on the density of the contaminants. The contaminated soil volume to the total slide volume should thus be considered. It should be decided what is worth protecting at the site, for example, a fresh water intake at the site or biodiversity and the establishment of organisms in the 'new' sediment. A contamination level should be determined as a criterion for failure. Such a failure criterion could for example be concentrations above EQS for the sediments. The amount of the sliding soil mass that will stay in the river at the site and the amount that instantaneously will go into 
suspension and be further transported away should be estimated. Mixing with sediment already in the river may occur and may dilute the particle bound fraction in the water column. There is a time aspect to be aware of as erosion of the runout deposits located beneath the water surface eventually begins.

- Failure, impact zone II: It should be decided what is worth protecting along the pathway, for example, a bathing area, a fresh water intake, or fishing and recreation areas. Thus, bathing water criteria, drinking water criteria, or environmental quality standards for fresh water and aquatic life can be used as criteria for failure. For European sites, the European Directives are relevant for failure definition (e.g., Water Framework Directives, Surface Water Abstraction Directive, Freshwater Fish Directives, Bathing water Directives, and Marine Strategy Directive). Exposure time and exposure level will have impact on the acute and chronic effects. In this case we only consider the instantaneous release and thus focus more on the acute consequences.

- Failure, impact zone III: Accumulation or receiving areas should be identified and a decision made on what is worth protecting in these areas. Although the environmental consequences will depend on the persistency, degradability, and chronic or acute toxicity of a substance, the suggestion is to evaluate the potential additional pollution a landslide may cause with regard to a background load and mean concentration, because of the large uncertainties concerning where the contaminants exactly will accumulate and in what form. The European Directives (see above) are relevant for determining failure criteria for European sites.

Note that each failure is regarded separately from the others even if there are relationships between them (e.g., a failure in zone II does not need to be preceded by a failure in zone I), because the probability of failure should be estimated at all locations.

\subsection{Deciding on probability models (step 3)}


Most risk assessment methods apply physical models to quantify the risk. The working approach suggested here explicitly accounts for parameter uncertainty in the physical models in order to estimate the probability of failure in each zone. This can be achieved by simulations, e.g., Monte Carlo techniques, where the parameter values in the physical models are represented by a probability distribution instead of a single value. The Monte Carlo simulation technique samples these distributions a defined number of times and generates a probability distribution as the final outcome for the variable studied.

The complexity of the model should be compatible with the quantity and quality of available data. High model complexity can give the impression of credibility, but a complex model does not compensate for lack of data, thus the apparent credibility may be misleading. Alternatives to simulations are available (Alén, 1998), but Monte Carlo techniques are often easily applied with an add-in to Excel such as Crystal Ball (Oracle, 2012) or @Risk6 (Palisade, 2013). In this study, slope failure is calculated using an analytical solution to a traditional slope stability model including parameter uncertainty (see Appendix A) instead of Monte Carlo simulations, i.e. the uncertainties are solved analytically, whereas Monte Carlo simulations are used in the physical models for the calculation of contamination failure.

\subsection{Setting parameter uncertainties (step 4)}

If there is an existing dataset for a parameter (e.g., flow velocity), the dataset can be evaluated by defining the parameters of their distribution. However, if there is no dataset available, the choice of distribution for a specific parameter should be carefully chosen based on similar datasets from the literature and/or using expert judgment. The choice is dependent on the type of parameter. A triangular distribution can, for example, be a suitable choice if the most likely value as well as the minimum and maximum values can be estimated. The uniform distribution would represent a situation with maximum uncertainty but with known minimum and maximum values. If no absolute minimum and maximum values can be estimated, however, or if the parameter is likely to have tails in one or two 
directions, these types of distribution are unsuitable and a normal or a lognormal distribution may be a good choice. For the landslide probability and the corresponding chosen basic model, the parameter uncertainties are described by lognormal distributions. In natural science, normal, lognormal, and exponential probability distributions are frequently used (Gordon et al., 2004; Parker et al., 1999; Grönholm and Annila, 2007).

\subsection{Computing probability of failure (step 5)}

The probabilistic model for each of the failure zones contains one or several physical models in which the parameter uncertainties in each of these models are defined in the earlier steps; thus the computation itself is now done by Monte Carlo simulation or by any other chosen method. In this step, the main issue is to make the results easily understandable to decision-makers in order to discuss the acceptable probability of failure. As earlier stated, the working mode is iterative and it is important to revise the calculations so that the results are reasonable and robust.

\subsection{Performing sensitivity analysis (step 6)}

A sensitivity analysis provides insight to the calculations since it allows the analyser to identify which parameters will have the greatest influence on the results of the calculations and gives input to whether collection of additional data is worthwhile or even necessary.

\section{Case study: Surte}

The property Surte 2:38 is located adjacent to the river Göta Älv in Sweden (Fig. 2). The study site is situated $8.4 \mathrm{~km}$ upstream of the raw water intake that supplies about 700000 inhabitants in Gothenburg with drinking water. The distance to the Gothenburg city centre is about $15 \mathrm{~km}$. 
Surte 2.38 is a former dump area that between the 1930's and 1960's was filled with residues from the old shipbuilding industry in Gothenburg. Material and soil deposits were also dumped in the river in order to expand the land area further into the river. The site has been classified according to the framework for risk classification of contaminated land of the Swedish Environmental Protection Agency (Naturvårdsverket, 1999) and it was judged to pose a very high risk (worst level of four levels in total).

The site contains a variety of contaminating metals and organic compounds. However, in this study we have focused on lead $(\mathrm{Pb})$ and mercury $(\mathrm{Hg})$, which were considered to provide design conditions for the risk assessment and the decision on remediation (SWECO VIAK, 2007). Both compounds are nonessential for humans, are persistent in the environment even though organic mercury is degradable, and have large adsorption capacity to particles.

A recent LRA, performed within the Göta Älv investigation (SGI, 2011) assessed a primary landslide area at the site with a probability $(P)$ of $10^{-4} \leq P<3 \times 10^{-3}$, and a secondary landslide area with a probability of $3 \times 10^{-6} \leq P<10^{-4}$. However, no time aspects were considered in the analysis and the landslide probability refers to parameter uncertainties in the calculations of factor of safety for each section. In our study time is included.

\subsection{Description of initial conditions (step 1)}

The study deals with the river Göta Älv downstream of the bifurcation near the town of Kungälv that discharges its water into the harbour and the inner estuary of the City of Gothenburg (Fig. 2). This river stretch has a rather flat floodplain that is surrounded by bedrock. The river is a national priority in terms of the protection of reproduction areas for eel and salmon. Both commercial and recreational fishing occur in the estuary and coastal area. There are bathing areas at several locations in the outer harbour and estuary. The river water quality is continuously monitored by the Recycling and Water Department of Gothenburg City (the Gothenburg water management) and the GÄVVF (the water quality association of the river Göta Älv). The water quality is considered good based on the available 
data. According to the water authority that implements the WFD in the region, a good ecological status will be achieved for the river; but good chemical status will not be attained in the harbour area.

Several industries are located along the river. In the City of Gothenburg, several areas have been identified that contain contaminating legacies from the past.. The annual load of $\mathrm{Pb}$ and $\mathrm{Hg}$ from the river Göta $\mathrm{Allv}$ is estimated to $1735 \mathrm{~kg} \mathrm{~Pb} /$ year and $8 \mathrm{~kg} \mathrm{Hg} /$ year, based on monthly data sampled at the freshwater intake by GÄVVF and data on river flow for the years 2002-2009.

The river water has a mean flow of $161 \mathrm{~m}^{3} / \mathrm{s}$ in the branch (measured between the years 2001-2009). Limited sedimentation occurs in the river upstream Gothenburg city and settlement and accumulation of particles take place only where the river widens and the water velocity decreases: from the city centre/inner harbour through the outer harbour and the estuary. This can be observed in the sediments deposited in the harbour and estuary area, which contain a mixture of all sorts of contaminants (Brack and Stevens, 2001; Brack, 2002; Brack et al., 2001b, 2001a; Johannesson et al., 2000). The sediments are considered as moderately to highly contaminated with respect to mercury, copper, lead, zinc, and PAH, PCB and tin organic compounds, all showing significantly elevated concentrations (Brack and Stevens, 2001). In the harbour and estuary, the pollution has been observed to effect fish (Sturve et al., 2005, 2006). Maintenance dredging is done every 3-5 years in the harbour area and polluted dredge materials need to be managed.

The river Göta Älv has a long landslide history, where some landslides have caused disastrous consequences including damaged and destroyed buildings, industrial facilities, and entire communities, as well as fatalities. The initial slides are classified as rotational slides around a circular failure plane and consist of a rather coherent moving soil mass of mainly clayey soil beneath filling material. As such, a greater proportion of the landslide deposit remains in the river at the site of the event. In areas where quick clay is present, slides have progressed both along the riverbank and upwards, encompassing very large areas. In case of a landslide, dredging will occur almost immediately to free the fairway as the river is an important channel for the Swedish import and export industry. 


\subsection{Defining failure (step 2)}

Defining failure for the case study focuses on the exposure mechanisms A, B and D in the conceptualisation above. The reasoning behind this is that dredging of the landslide deposit in the studied river will most certainly take place within a short period of time after the slide event.

The overall aim of the European Water Framework Directive (WFD) and the Marine Strategy Directive (MSD) is that all waters are protectable. These directives thus provide a basis for the definition of undesirable events and failures at each of the impact zones together with national and local environmental goals.

The undesirable event in impact zone I is defined as the occurrence of a bottom sediment that does not promote the (re-)establishment and growth of species. A failure criterion is here defined as having a sediment with a mean concentration of $\mathrm{Pb}$ or $\mathrm{Hg}$ above $\mathrm{EQS}$ for $\mathrm{Pb}$ and $\mathrm{Hg}$ in sediment. There are no Swedish EQS for $\mathrm{Pb}$ and $\mathrm{Hg}$ in sediment and the Canadian Interim Sediment Quality Guidelines Sediment Screening Benchmark (CISQG) values are used (RAIS, 2012). The CISQG values indicate threshold levels below which adverse biological effects are not expected.

The undesirable event in impact zone II is defined as reaching a level of acute toxicity in the water for fish and other living organisms, but also if contaminated water enters the water intake. In this case it is therefore relevant with two sub-zones: (a) one for the river water closest to the site of the event, because the highest concentration will occur closest to the landslide deposit; and (b) the other for the water intake. Swedish EQS for $\mathrm{Pb}$ and $\mathrm{Hg}$ in freshwater are missing and international EQS was used again.

The failure in impact zone IIa is defined as the probability to reach an instantaneous water concentration above acute toxicity levels, chosen to be the Acute National Ambient Water Quality Criteria (ANAWQC) (RAIS, 2012).

The second failure, impact zone IIb, is defined as a water concentration above the Swedish drinking water guideline value (which is the same as the European Drinking Water Directive 98/83/EC, 
EDWD) at the water intake. On average, the water intake is closed approximately 100 days a year due to excessive turbidity levels (associated with pathogens and contaminants), salt water intrusion, or if the water management has received information on spills or accidents.

The undesirable event in impact zone III is defined from the contribution to the deterioration of the river mouth and estuary, implying an additional stress to the organisms. It is generally more interesting to look at total quantities for persistent and chronic toxic substances, whereas concentrations and concentration peaks are important for acute toxic biodegradable and dilutable substances. $\mathrm{Pb}$ and $\mathrm{Hg}$ are assumed to belong to the former and failure is therefore defined from a load perspective with respect to the environmental goals for the region, as formulated by the City of Gothenburg.

A failure criterion in impact zone III is defined based on what can be transported to the accumulation or receiving areas from the studied landslide and in relation to the background pollution load of $\mathrm{Pb}$ and $\mathrm{Hg}$ from the river. An accumulation area is not completely static and sediments are re-suspended and further transported to the continental shelf during high flow velocities (Sunderland et al., 2012) and critical contaminant concentrations in sediment can be an option for failure criteria. However, sediment concentrations are note only relying on the contribution from the landslide. Working with load instead of concentrations in impact zone III appeared to be more reasonable for our case. The additional load a landslide could cause to the system is hence considered. The definition is not unproblematic, and defining a critical level, either from a non-acceptable or ecosystem tipping point aspect, proved to be quite difficult because no authority could specify acceptable levels or locations of ecosystem tipping points. Thus, three levels of critical loads were investigated: additional loads $(W)$ of $1 \%, 10 \%$, and $50 \%$ of the background load $\left(W_{b g}\right)$. The background load was calculated at the water intake, which is the sampling point used by the GÄVVF.

The failure criterion for each zone is shown in Table 2.

\subsection{Deciding on probability models (step 3)}


To reduce the complexity, an analytical solution is applied for the calculation of landslide probabilities, and an analytical solution to the advection-dispersion equation is employed to compute the probability of failure in impact zones II and III. The advection-dispersion equation assumes homogeneous conditions along the transport pathway and does not describe heterogeneities. The time aspect for the landslide is considered by specifying the landslide probability for an arbitrarily chosen reference time. The analysis of the case study does not account for second-order uncertainties (i.e., uncertainties about probabilities) and model uncertainties are not explicitly considered. However, the suggested approach allows for considering these aspects as well.

Failure in impact zone $\mathrm{I}$ is defined as the mean concentration $\left(\mu_{\text {sed }}\right)$ of $\mathrm{Pb}$ or $\mathrm{Hg}$ in the runout deposits $>$ CISQG. To calculate the probability of failure in zone $\mathrm{I}\left(P_{f, I}\right)$, the probability of this event needs to be multiplied with the probability of a landslide $\left(P_{L}\right)$ at the site:

$P_{f, I}=P_{L} \times P\left[\mu_{\text {sed }}>\mathrm{CISQG}\right]$

Failure in impact zone IIa is defined as the occurrence of a mean concentration $\left(\mu_{w}\right)$ of $\mathrm{Pb}$ or $\mathrm{Hg}$ in the water $>$ ANAWQC. To calculate the probability of failure in zone IIa $\left(P_{f, I I}\right)$, the probability of this event also needs to be multiplied with the probability of a landslide at the site:

$P_{f, I I a}=P_{L} \times P\left[\mu_{w}>\right.$ ANAWQC $]$

Failure in impact zone IIb is defined as the occurrence of a water concentration $\left(c_{w}\right)$ of $\mathrm{Pb}$ or $\mathrm{Hg}$ at the water intake $>$ EDWD. The probability of failure in zone $\operatorname{IIb}\left(P_{f, I l b}\right)$ is defined as: 


$$
P_{f, I I b}=P_{L} \times P\left[c_{w}>\text { EDWD }\right] \times P_{r w}
$$

where $P_{r w}$ is the probability that the water intake is open when the contaminant pulse passes the intake.

Failure in impact zone III is defined as an additional load $(W)$ of $\mathrm{Pb}$ or $\mathrm{Hg}$ from the landslide at the point of interest, chosen to be downstream of the water intake in order to compare with load calculations by GÄVVF. The probability of failure in zone III $\left(P_{f, I I I}\right)$ is defined as:

$P_{f, I I I}=P_{L} \times P\left[W>\alpha W_{b g}\right]$

where $\alpha$ is 1,10 or $50 \%$ of the background load $\left(W_{b g}\right)$, i.e., the diffuse pollution load.

\subsubsection{Calculation of $\boldsymbol{P}_{L}$}

Calculations of the probability of a landslide along the river Göta Älv were recently carried out by the Swedish Geotechnical Institute (SGI) as a part of a three-year government mandate to determine the landslide risk in the Göta Älv river valley (SGI, 2011). The methodology is reported in Berggren et al. (2011) and was developed from Alén (1998). In summary, the mathematical model is based on a number of geotechnical cross-sections and the calculation of a probability to achieve a slope safety factor below one. Areas between these sections are expert judged, as was the case for our case study area. Alternative methods for the assessment of landslide probability are presented in, for example, AGS (2000), Lee and Jones (2004), Michael-Leiba et al. (2003), Roslee et al. (2012), and Geertsema et al. (2009). Listo and Vieira (2012) defined landslide probability as a combination of geotechnical and geological conditions, in addition to expert judgements. 
In the Göta Älv study, the site Surte 2:38 was assessed to be a primary landslide area with a landslide probability of $0.0001-0.003$. However, in the analysis no time scale was considered although the model description accounted for it. For the present case study, the landslide probability was recalculated and a reference time for the probability was incorporated in the analysis. Figures $3 \mathrm{a}$ and $3 \mathrm{~b}$ show the schematic models for the slope stability analysis and the erosion in the river. Figure $3 \mathrm{a}$ shows the theory behind a rotational landslide with a slip surface that is typical for the area, and Fig. $3 \mathrm{~b}$ shows how erosion is included in the model. Erosion is used as the time variable to calculate changes in geometry by a certain time limit together with water level variations, affecting the changes in safety factor by time. The calculated landslide probability as a function of a chosen reference time is shown in Fig. 4 (see Appendix A for further explanation). For comparison, the landslide probability is shown both with and without considering erosion and for the reference time. A description of the landslide analysis methodology is given in Appendix A. The default reference time in the Eurocode system $(\mathrm{EN} 1990,2002)$ is 50 years, which was also chosen in this study. Hence, the landslide probability becomes $P_{L}=0.003$ (see Appendix A and Fig. 4). As mentioned, no second-order uncertainty is considered here and the probability of a landslide is calculated as a point estimate.

\subsubsection{Calculation of $P\left[\mu_{\text {sed }}>\right.$ CISQG $]$}

Data from soil investigations at the site were used to assess the probability that the landslide deposits are contaminated. In the analysis, we only account for the part of the soil that is heavily contaminated, i.e. the uppermost two meters. The survey was conducted by a consultancy firm (SWECO VIAK, 2007) on behalf of Ale municipality. We hypothesised that the mean concentration of $\mathrm{Pb}\left(\mu_{\text {soil, } P b}\right)$ and $\mathrm{Hg}\left(\mu_{\text {soil, } H g}\right)$ in the soil will be the same when the soil is deposited in the river, $\mu_{\text {sed, } P b}$ and $\mu_{\text {sed, } H g}$ respectively. The probability that the mean concentration is exceeding the CISQG guideline value is estimated by performing a one-sided hypothesis test. Here, the Chen test (US EPA, 2006) was used as data was found to be very skew and could be assumed to follow a lognormal distribution. The nullhypothesis was formulated as $\mathrm{H}_{0}: \mu_{\text {sed }} \leq \mathrm{CISQG}$, and the corresponding $p$-values for $\mathrm{Pb}$ and $\mathrm{Hg}$ were 
$7 \times 10^{-11}$ and $2 \times 10^{-9}$, respectively. From this it was concluded that $P\left[\mu_{\text {sed }}>\right.$ CISQG] is essentially 1 for both $\mathrm{Pb}$ and $\mathrm{Hg}$. Summary statistics of the sample data for $\mathrm{Pb}$ and $\mathrm{Hg}$ can be found in Table 3 .

\subsubsection{Calculation of $P\left[\mu_{w}>\right.$ ANAWQC $]$}

The advection-dispersion equation (ADE) could be employed to calculate a mean concentration in the water from the landslide (see Göransson et al., 2012), but as the transport and mixing are quite complicated during this phase, the ADE was not considered appropriate to use at the site for the event. Instead a simple calculation approach was taken and the concentrations of $\mathrm{Pb}$ and $\mathrm{Hg}$ in the water, from the landslide runout deposits, were estimated by dividing the amount of contaminant times an estimated proportion of contaminated soil material in suspension (not all contaminants are released into the water column instantaneously) with the volume of water:

$$
\mu_{w}=\frac{\left(\mu_{\text {soil }} \times \rho \times A_{L} \times d \times S\right)}{L_{L} \times A_{E}}
$$

where $\mu_{\text {soil }}$ is the mean concentration of $\mathrm{Pb}$ or $\mathrm{Hg}$ in the soil, $\rho$ is the soil density, $A_{L}$ is the landslide area, $d$ is the depth of the contaminated soil, $S$ is the ratio of the contaminated soil that is estimated to be released into the water column as a result of the landslide, $L_{L}$ is the landslide length along the riverbank, and $A_{E}$ is the river cross-sectional area at the site for the event.

\subsubsection{Calculation of $P\left[c_{w}>\right.$ EDWD $]$}

Sediment released from land into a river will be transported downstream by the mean flow (advection), simultaneously as the material is subject to mixing in the water column through dispersion and to deposition at the bed due to the gravitational forces. Here an analytical approach is 
taken by using the $\mathrm{ADE}$ to describe the concentration variation in the river after the sediment release. As mentioned, there are limitations to analytical solutions but it is considered a good approximation for the present case; see also Göransson et al. (2012).

In impact zone IIb, the one-dimensional ADE was therefore applied in order to calculate and estimate the probability of failure. The ADE is written with sediment settling as a sink term (sediment deposition, which is settlement of contaminants bound to particles) for the transport (see Appendix B):

$$
\frac{\partial c}{\partial t}+U \frac{\partial c}{\partial x}=D \frac{\partial^{2} c}{\partial x^{2}}-\frac{w c}{h}
$$

where $c$ is the mean concentration (mass per unit volume), $U$ the mean velocity in the river, $D$ the dispersion coefficient, $w$ the settling velocity, $h$ the water depth, $x$ the spatial coordinate along the river, and $t$ the time. The equation describes how sediment is transported downstream with the mean velocity (advection), at the same time being subject to mixing (dispersion) and settling at the bottom. The solution to Eq. 6 for the instantaneous release of a contaminant mass $M_{\text {Susp }}(\mathrm{kg})$ at $x=0$ and $t=0$ is:

$$
c_{w}=\frac{M_{\text {Susp }}}{A \sqrt{4 \pi D t}} \exp \left(-\frac{(x-U t)^{2}}{4 D t}-\frac{w t}{h}\right)
$$

where $A$ is the mean cross-sectional area of the river. In order to obtain the concentration at the intake $\left(c_{w}\right)$ at any given time, $x=x_{w}$ in Eq. 7, where $x_{w}$ is the distance to the water intake from the location of the slide. This equation represents a concentration distribution that follows a Gaussian shape in space at any given time, where the centreline of the distribution moves downstream with the velocity $U$. The 
dispersion coefficient $D$ is a parameter which is difficult to estimate. It could have been chosen as a stochastic variable, but for this case, $D$ is computed with the formula described in Appendix B.

\subsubsection{Calculation of $\boldsymbol{P}_{r w}$}

The freshwater intake is closed approximately 100 days per year for the reasons described in section 4.2. The probability that the water intake is open $\left(P_{r w}\right)$ is calculated as $265 / 365=0.726$. There is a possibility that the water supply plant will be informed about the slide in time to close the intake. This possibility will however depend on how close the slide is to the water intake, if the landslide occurs during day or night time, if it is large enough to be noticed by the neighbouring people, or if it is closed for other reasons. In the present case, for simplicity, $P_{r w}$ is treated as a random variable.

\subsubsection{Calculation of $P\left[W>\alpha W_{b g}\right]$}

In impact zone III it is of interest to estimate how much of the released sediment that is deposited upstream a certain location or, equivalently, the amount of material that is transported past the location.

Particles and particle bound contaminants settle as the river mouth widens and fresh water meets marine water, which causes the particles to form aggregates. The contaminants will most likely be distributed over large areas and the uncertainties where these contaminants will settle and the possible consequences they may pose are hence large. To simplify, we continue to use the one-dimensional $\mathrm{ADE}$ (Eq. 7) to calculate the amount of $\mathrm{Pb}$ and $\mathrm{Hg}$ passing a certain point, here chosen to be the water intake.

The material passing the intake can be obtained as the difference between the total amount of material released $\left(M_{\text {susp }}\right)$ and the material deposited upstream $\left(Q_{B U}\right)$. Based on the analytical solution, the relationship between these two parameters is given by (see Appendix B for the derivation): 


$$
\frac{Q_{B U}}{M_{\text {Susp }}}=1-\frac{2 \lambda}{1+4 \lambda-\sqrt{1+4 \lambda}} \exp \left(-\frac{1}{2} \eta(\sqrt{1+4 \lambda}-1)\right)
$$

where $\lambda$ is a non-dimensional quantity calculated as $w D / U^{2} h$, and $\eta$ is a non-dimensional quantity calculated as $x U / D$. The ratio of the released material passing the point $\left(S_{M}\right)$ is calculated as 1$Q_{B U} / M_{\text {Susp }}$, and finally, the amount $(W)$ deposited downstream the point is determined from $M_{\text {Susp }} \times S_{M}$.

\subsection{Setting parameter uncertainties (step 4)}

In order to model the uncertainties, each parameter in the equations is assigned a probability distribution. The probability distributions are based either on measurements or a best estimate from data and the literature. The chosen probability distributions and associated motivations are given in Table 3.

\subsection{Computing probabilities of failure (step 5)}

The probabilities to exceed EQS in the different impact zones were obtained by Monte Carlosimulations (50,000 runs) using Crystal Ball (Oracle, 2012). The simulations were also tested for 10,000 runs, which showed a marginal difference $(0-0.6 \%)$ in the results. No correlations between input parameters were assumed. The slope failure probability $\left(P_{L}\right)$ and the probability of the water intake being open $\left(P_{r w}\right)$ were also treated as point estimates. The final results are presented in Table 4 which shows the probabilities to exceed the EQS, and the resulting probabilities of failure for $\mathrm{Pb}$ and $\mathrm{Hg}$, i.e., the quantitative risk estimates. 


\subsection{Performing sensitivity analysis (step 6)}

The most influential parameter for the probabilities of failure is the estimated probability for a landslide to occur. The sensitivity analysis from the Monte Carlo simulations shows that there are primarily three parameters which have the largest influence on the result of the simulations. These parameters are: (1) the mean concentration of the contaminant $\left(\mu_{\text {soil }}\right)$, (2) the proportion of contaminants in the soil that is instantaneously released to the water $(R)$, and (3) the settling velocity (w) (the effective settling velocity if data for such calculations are available (Hamm et al., 2011)), which is the sink term in the ADE. For example, approximately $65 \%$ of the variation in the results of the calculated mean water concentration close to the runout (i.e., $x=0 \mathrm{~m}$ ) is due to the variation in $\mu_{\text {soil }}$. The contributions from the different parameters are shown in Table 5 for each type of simulation. These three parameters are also the ones which are most uncertain. The uncertainty in the estimation of $\mu_{\text {soil }}$ and the settling velocity ( $w$ ) can be decreased by collecting additional data on contaminant concentrations and on soil particle distributions. The proportion of contaminants in the soil that is instantaneously released to the water $(R)$ is a parameter which must be estimated. This estimation could be improved by investigating data from previous landslides that are of similar character as the possible landslide studied. However, the first step to improve the risk estimation would be to update the calculations of the probability for the landslide, which would require further field studies and collection of data.

\section{Discussion}

\subsection{Case study: Surte}

In the calculations, the probability of a landslide $\left(P_{L}\right)$ will have a large influence on the probability of failure $\left(P_{f}\right)$. Here, $P_{L}$ is chosen as the highest probability estimated for the area around Surte 2:38. It is thus likely that $P_{L}$ (and correspondingly $P_{f}$ ) is lower than $0.3 \%$. The calculated probabilities of failure based on this estimate of $P_{L}$ vary from $0.3 \%$ down to $0.09 \%$ (see Table A.2 in Appendix A) for a time 
period of 50 years, considering erosion. If erosion is not considered, the probability lies around $0.15 \%$ (Fig. 4).

However, given that the landslide occurs, it can be concluded that the landslide deposit (impact zone I) will contain a mean concentration of $\mathrm{Pb}$ and $\mathrm{Hg}$ above EQS for sediments, which was shown to be in the range of 190 and 230 times the EQS values, respectively. The probability to exceed the guideline values for contaminated sediments is therefore essentially $100 \%$ given that the landslide occurs, which also means that the landslide deposit will act as a contaminant hotspot. If the landslide deposit in the river is not remediated immediately (i.e., using dredging), contaminants will slowly be released into the water column as soon as diffusion and erosion start. For the river Göta Älv, the landslide deposit in the river will most certainly be dredged in order to clear the fairway for vessels. The contaminants will however be available for exposure before dredging is carried out and the instantaneous impacts are therefore still relevant to study.

The contaminants that are released from the landslide deposit are assumed to be transported as a pulse (as opposed to a continuous injection). Thus, the concentration in the water close to the slide area will initially be high, but as a result of advection and dispersion the peak concentration decreases along the pathway and the pulse is increasingly dispersed in time. Given the landslide, the probability that a concentration in the water will exceed acute toxicity (ANAWQC) is essentially $100 \%$ at the location of the landslide (impact zone IIa). In this investigation, the impact of exposure time on toxicity is not analysed but there are studies that emphasise the relationship between toxicity and exposure time. Acute toxicity may occur also at very short exposure times, depending on the organism and compound tested (Parsons and Surgeoner, 1991; Preston et al., 2000). Studies have also shown that a sudden release of contaminants does have effects on the fish in an estuary (Sturve et al., 2005, 2006). There is thus a potential that a landslide of contaminated soil also may have such an impact. However, further studies are needed to analyse the time dependency and this is recommended as future work.

The probability of a concentration of $\mathrm{Pb}$ above drinking water standards at the water intake $8.4 \mathrm{~km}$ downstream the slide area (impact zone IIb) given that the landslide occurs is about $65 \%$, whereas the 
corresponding probability for $\mathrm{Hg}$ is about $9.5 \%$. Taking into account that the water intake might be closed, the probability for failure decreases to $47 \%$, respectively $6.9 \%$, which most likely is an overestimation considering the possibility of warnings.

Based on the $\mathrm{ADE}$ it was found that a $\mathrm{Pb}$ concentration above the drinking water standards (EDWD) at the raw water intake may last as long as 11 hours while the pulse passes the water intake (about 3 hours for $\mathrm{Hg}$ ). In the case of the river Göta Älv, the water management has a warning system consisting of on-line turbidity measurements and continuous e-coli analysis. However, the intake does not close until the turbidity reaches a specific level and after a certain time. This means that it is possible that the intake will not close in time to prevent contaminants from getting into the water supply plant. Possible consequences for the water supply plant, if harmful substances enters, have not been considered in this study but was partly done by Lindhe et al. $(2011,2009)$.

The probability that the landslide could cause an additional load of $\mathrm{Pb}$ and $\mathrm{Hg}$ to the accumulation areas (zone III) above 1, 10 and 50\% of the annual load (i.e., the background load) was also assessed. The case study shows that if the primary landslide area slides into the river, a significant additional load of contaminants to the system is possible. With a probability of $80 \%$ and $82 \%$ the additional load corresponds to more than $1 \%$ of the annual $\mathrm{Pb}$ and $\mathrm{Hg}$ load, respectively. With a probability of $32 \%$ and $36 \%$ the additional load corresponds to more than $10 \%$ of the annual $\mathrm{Pb}$ and $\mathrm{Hg}$ load, respectively. Finally, with a probability of $9 \%$ and $10 \%$ the additional load corresponds to more than $50 \%$ of the annual $\mathrm{Pb}$ and $\mathrm{Hg}$ load, respectively. These probabilities are relatively high; thus the contaminant contribution from a landslide in Surte 2:38 should not be neglected. The contribution to the chronic toxicity of the organisms in the accumulation areas is however not investigated in this study but is recommended as future work.

The probabilities for failure in the different impact zones are estimated to range between $0.3 \%$ and $0.002 \%$. To judge whether these constitute unacceptable probabilities of failure is not easy since there are no established criteria to compare with. Given that a landslide actually will take place in Surte 2:38 involving the contaminated masses, the probabilities are instead ranging from $9 \%$ to essentially $100 \%$. 
It is however difficult to argue that the risk to the fresh water supply is high considering a probability of failure of $0.1 \%$ with regard to $\mathrm{Pb}$. Also, because there is a warning system, the high concentrations will only remain for a short period of time, and there is a possibility to take water from a reservoir during the shut-down of the intake. The risk for negative consequences in the river is estimated to be more serious with regard to the aquatic life in the form of acute toxicity and the overall load to the estuary.

Surte 2:38 is at present subject to remediation that will be finalised in 2013. Until then, about 70000 tons of contaminated soil will be excavated and transported to a disposal site. Before this excavation could be carried out, pressure banks along the river were laid out to prevent the land from sliding into the river. The total cost for the remediation is estimated to approximately 12.4 million $€$ (109 million SEK) and is funded up to $95 \%$ by the Swedish EPA. This cost includes remediation of a larger area than what is studied here as well as the stabilising actions in this area. Thus, in the case of Surte 2:38, the risk will be reduced both by means of lowering the contaminant concentrations in the masses and by lowering the landslide probability.

SWECO VIAK (2007) carried out the human health and environmental risk assessment at Surte 2:38. The overall conclusion from the assessment was that two main risks are related to transport of contaminants from the site. First, the risk of negative consequences to the drinking water supply system due to a landslide involving contaminated masses was assessed to be the most serious risk, where the negative consequences are due to loss of trust rather than health or environmental aspects. Second, continuous leakage of methylated mercury from the site into the river Göta Älv was assessed to possibly be significant. Consequences to the aquatic life are mentioned but not assessed.

This study shows that the probabilities of exceeding EQS (CISQG, ANAWQC) are high if a landslide occurs and that a landslide with a high probability contributes to a significant increase in the contaminant load to the estuary, even if the consequences of this are not assessed. However, to motivate full soil remediation of the site solely based on this may be questionable. Instead, stabilising measures are likely to cost-effectively lower the probabilities for a slide and thus the negative 
consequences related to that event. A rough estimate of the costs for decreasing the landslide probability for Surte 2:38 with two orders of magnitude to a $P_{L}$ approximately $10^{-5}$ lies in the range of 2.9-5.1 million $€$ (25-45 million SEK) (Hultén, C., Swedish Geotechnical Institute, personal communication). Increasing the slope stability does not necessarily hinder continuous leakage of methylated mercury from the site, but a full excavation of the contaminated soil and subsequent transport to landfills should be motivated by other unacceptable risks (e.g., human health, risks to soil ecosystem) than those brought forward in the report by SWECO VIAK (2007). In addition to the financial costs for remediation, e.g., the environmental costs of transports and landfilling, the increased risks due to transport and emissions during the remediation activities may be significant.

In Sweden, the Swedish EPA does not finance stabilising measures; instead these can be financed by the Swedish Civil Contingencies Agency and the Swedish Transport Administration. From the Swedish Civil Contingencies Agency's point of view, the consequences of a possible landslide at Surte 2:38 are not enough to motivate the need for increased stability as they only consider consequences to existing buildings, constructions, and important societal services. The Swedish Transport Administration handles consequences to infrastructure. Thus, there is a need for intersectoral solutions and management of contaminated sites with stability problems, which is a reality along many rivers.

\subsection{The suggested approach}

The suggested approach is not meant to replace either ERA or LRA, but to complement them. By adding this type of result to an ERA or an LRA, the suggested approach can act as a basis for communication and discussion in order to identify cost-effective intersectoral management solutions for those sites. The suggested approach shows that it is possible to make better assessments of possible risks than pure speculation, even though the assessment is based on sparse data and contains large uncertainties. The approach can also be used in river basin management when estimating sediment and water quality and contaminant load, although the case study in this paper does not illustrate this. 
In this study, the environmental consequences are described from the point of view of exceeding environmental quality standards (EQS). Although the ecological consequences are not described and valued here, the approach is not limited only to the use of EQS. Instead, the approach can be complemented with studies on environmental or health consequences, and possibly value these in monetary terms. However, this may be complicated as the consequences typically are dependent on the concentration, thus, the probabilities must be simulated for different levels and then integrated to yield a total risk. Nevertheless, examples of consequences that would be relevant to study are loss of benthic organisms, loss of fish species, and loss of bathing areas. Estimations in monetary terms have the advantage of being clear about values. The difficulties, on the other hand, are that environmental consequences are in general difficult to value economically.

There are typically large uncertainties in data and knowledge, but the proposed methodology offers a framework for managing this rather typical situation. Parameter uncertainty is explicitly treated, whereas model uncertainty is not treated in this case study. There are for example limitations to the application of an analytical advection-dispersion solution that are not considered in this case study. The general approach however allows for including model uncertainties. The input data to the ADE model are estimated both based on available data and expert judgment, and the sensitivity analysis provides information about where the largest parameter uncertainties lay and can direct further data collection. The approach to estimate the landslide probability (Appendix A) is assumed to be suitable for the site-specific conditions in the river Göta Älv. However, in other settings different models may be more suitable. Other examples of such calculations can be found in, e.g., Corominas and Moya (2008), Fannin and Wise (2001), Malkawi et al. (2001), and Roslee et al. (2012). The landslide probability was calculated to be 0.003 and this may be seen as low. However, in comparison with acceptable probabilities of fatal disasters with regard to buildings and other facilities, which typically is in the order of $5 \times 10^{-5}$ (Gulvanessian et al., 2002), the estimated probability of a landslide may be regarded as relatively high. In an LRA, however, not only the landslide probability is included, but the risk constitutes the combination of the probability and the consequences associated with a landslide. 
The analysis of this case study represents a rather typical situation in these types of probabilistic risk assessments. Several different, more or less complex, site-specific and general models and assumptions are used and the input data are a mix of site-specific data, general data, and expert judgment. An advantage of the suggested general approach is that when new data and knowledge become available, all calculations and models can be updated.

\section{Conclusions}

The general conclusions from this study are that the suggested approach:

- provides a quantitative analysis of the risks associated with landslides in contaminated area,

- makes the problem with slope instability in contaminated sites visible; and

- acts as a basis for communication and discussion thereby contributing to intersectoral management solutions.

Specific conclusions from the case study Surte 2:38 are that:

- the probabilities for failure are low, but given a landslide, the probabilities of exceeding EQSs are high,

- given a landslide, the probabilities that the slide would contribute to a significant increase in contaminant load is high; and

- stabilising measures are likely to cost-effectively lower the probabilities for negative environmental consequences sufficiently.

\section{Acknowledgements}

This study was financed by the Swedish Geotechnical Institute (SGI) and the national research fund Formas (Grant 245-2007-786). The authors especially wish to thank Karin Blechingberg at the Ale Municipality for the provision of data and information on the case study site and Tommy Norberg 
from Chalmers University of Technology for the discussions on the statistics. Carina Hultén (SGI) is acknowledged for sharing her insights on the financing system for slope stabilisation measures. The authors also would like to acknowledge Lars Förlin at the University of Gothenburg, Department of Biological and Environmental Science, Ann-Sofie Wernersson at the Swedish Agency for Marine and Water Management, and Åsa Axhede and Tommy Hammar at the County Administrative Board of Kalmar, for valuable input to the definitions of failure criteria. Finally, the comments from three anonymous reviewers are greatly appreciated and significantly improved the paper. 


\section{References}

AGS. Landslide Risk Management Concepts and Guidelines. Australian Geomechanics Society, SubCommittee on Landslide Risk Management, 2000.

Alén C. Application of a probabilistic approach in slope stability analyses. Proceedings of the 7th International Symposium on Landslides 1996;2.

Alén C. On Probability in Geotechnics. Random Calculation Models Exemplified on Slope Stability Analysis and Ground-Superstructure Interaction. Department of Geotechnical Engineering; 1998.

Attiwill PM. The disturbance of forest ecosystems: the ecological basis for conservative management. Forest Ecology and Management 1994;63: 247-300.

Berggren B, Alén C, Bengtsson PE. Falemo S. Methodology for assessment of landslides probability: Quantitative model (in Swedish: Metodbeskrivning sannolikhet för skred: Kvantitativ beräkningsmodell). Swedish Geotechnical Institution, Linköping; 2011.

Blanck H. A Critical Review of Procedures and Approaches Used for Assessing Pollution-Induced Community Tolerance (PICT) in Biotic Communities. Human and Ecological Risk Assessment: An International Journal 2002;8:1003-1034.

Bonnard C, Forlati F, Scavia C. Identification and mitigation of large landslide risks in Europe. Advances in risk assessment., 1st ed. A.A. Balkema Publischers; 2004.

Borgatti L, Soldati M. Landslides as a geomorphological proxy for climate change: A record from the Dolomites (northern Italy). Geomorphology 2010;120: 56-64.

Brack K. Organotin Compounds in Sediments from the Göta Älv Estuary. Water, Air, \& Soil Pollution 2002;135: 131-140.

Brack K, Johannesson LT, Stevens RL. Accumulation rates and mass calculations of $\mathrm{Zn}$ and $\mathrm{Hg}$ in recent sediments, Gota alv estuary, Sweden. Environmental Geology 2001a;40: 1232-1241. 
Brack K, Stevens RL. Historical pollution trends in a disturbed, estuarine sedimentary environment, SW Sweden. Environmental Geology 2001;40:1017-1029.

Brack KB, Johannesson LJ, Stevens RS. Accumulation rates and mass calculations of $\mathrm{Zn}$ and $\mathrm{Hg}$ in recent sediments, Göta Älv estuary, Sweden. Environmental Geology 2001b;40: 1232-1241.

Corominas J, Moya J. A review of assessing landslide frequency for hazard zoning purposes. Engineering Geology 2008;102:193-213.

Crozier MJ. Deciphering the effect of climate change on landslide activity: A review. Geomorphology 2010;124:260-267.

Diaz-Cruz MS, Darbra RM, Barceló D. Monitoring and assessment of river pollutants: Report on the 1st Thematic Workshop of the EU-funded RISKBASE Coordination Action, held in Lisbon, Portugal, 17-18 May 2007. TrAC Trends in Analytical Chemistry 2007;26:650-658.

EN 1990. Eurocode - Basis of structural design, Annexes B and C. 2002.

Fannin RJ, Wise MP. An empirical-statistical model for debris flow travel distance. Canadian Geotechnical Journal 2001;38:982-994.

Finkel M, Barth J, Grathwohl P. Advanced tools and models to improve river basin management in Europe in the context of climate change, AguaTerra9 2010;128.

Folke C, Carpenter S, Walker B, Scheffer M, Elmqvist Th, Gunderson L. Regime Shifts, Resilience, and Biodiversity in Ecosystem Management. Annual Review of Ecology, Evolution, and Systematics 2004;35: 557-581.

Geertsema M, Pojar JJ. Influence of landslides on biophysical diversity - A perspective from British Columbia. Geomorphology 2007;89: 55-69.

Gordon D, Finlayson BL, McMahon TA. Stream Hydrology: An Introduction for Ecologists 2004;429.

Grönholm T, Annila A. Natural distribution. Mathematical biosciences 2007;210:659-67. 
Gulvanessian H, Calgaro JA, Holický M. Designers' guide to EN 1990: Eurocode: basis of structural design. Thomas Telford, London; 2002.

Göransson G, Larson M, Bendz D, Åkesson M. Mass transport of contaminated soil released into surface water by landslides (Göta River, SW Sweden). Hydrology and Earth System Sciences 2012;16:1879-1893.

Göransson G, Bendz D, Larson M. Combining landslide and contaminant risk: a preliminary assessment. Journal of Soils and Sediments 2009;9:33-45.

Hamm NT, Dade WB, Renshaw CE. Fine particle deposition to porous beds. Water resources research $2001 ; 47$.

Holling CS. Resilience and Stability of Ecological Systems. Annual Review of Ecology and Systematics 1973;4:1-23.

Jakob M, Lambert S. Climate change effects on landslides along the southwest coast of British Columbia. Geomorphology 2009;107:275-284.

Janbu N. Stability analysis of slopes with dimensionless parameters, Doctoral Thesis, MIT Cambridge, Massachusetts; 1954.

Johannesson L, Stevens R, Alexanderson J. Sediment Character in a Micro-Tidal, Harbor-Estuary Environment, Göteborg, Sweden. Estuaries 2000;23,400-410.

Kashefipour SM, Falconer RA. Longitudinal dispersion coefficients in natural channels. Water Research 2002;36:1596-1608.

Klimeš J, Novotný R. Landslide susceptibility assessment in urbanized areas: example from flysch carpathians, Czech Republic. Acta Geody. Geomater 2011; 8:443-452.

Kuriakose S, Sankar G, Muraleedharan C. History of landslide susceptibility and a chorology of landslide-prone areas in the Western Ghats of Kerala, India. Environmental Geology 2009;57:1553-1568. 
Landis WG. Regional scale ecological risk assessment: Using the relative risk model. CRC Press LLC; 2004.

Larsen MC. Rainfall-triggered landslides, anthropogenic hazards, and mitigation strategies. Advances in Geosciences 2008;14:147-153.

Lee .M, Jones DKC. Landslide risk assessment, 1st ed. Thomas Telford Ltd, London; 2004.

Li, X, Wang A, Wang Z. Stability analysis and monitoring study of Jijia River landslide based on WebGIS. Journal of Coal Science and Engineering (China) 2010;16:41-46.

Lindhe A, Rosén L, Norberg T, Bergstedt O, Pettersson Th. Cost-effectiveness analysis of riskreduction measures to reach water safety targets. Water Research 2011;45:241-253.

Lindhe A, Rosén L, Norberg T, Bergstedt O. Fault tree analysis for integrated and probabilistic risk analysis of drinking water systems. Water Research2009;43:1641-1653.

Listo FLR, Vieira BC. Mapping of risk and susceptibility of shallow-landslide in the city of São Paulo, Brazil. Geomorphology 2012; 169-170: 30-44.

Malkawi AH, Assan WF, Sarma SK. An efficient search method for finding the critical circular slip surface using the Monte Carlo technique. Canadian Geotechnical Journal 2001;38:1081-1089.

Marcus WA, Meyer GA, Nimmo DWR. Geomorphic control of persistent mine impacts in a Yellowstone Park stream and implications for the recovery of fluvial systems. Geology 2001; 29:355-358.

Michael-Leiba M, Baynes F, Scott G, Granger K. Regional landslide risk to the Cairns community. Natural Hazards 2003;30:233-249.

Naturvårdsverket. Metodik för inventering av förorenade områden. Naturvårdsverket (Swedish Environmental Protection Agency), Stockholm; 1999. 
Ohlson DW, Serveiss VB. The integration of ecological risk assessment and structured decision making into watershed management. Integrated Environmental Assessment and Management $2007 ; 3: 118-128$.

Oracle. Oracle Crystal Ball; 2012

Palisade. @RISK6; 2013

Parker KR, Maki AW, Harner EJ. There Is No Need To Be Normal: Generalized Linear Models of Natural Variation. Human and Ecological Risk Assessment: An international Journal 1999;5:355374.

Parsons JT, Surgeoner GA. Effect of exposure time on the acute toxicities of permethrin, fenitrothion, carbaryl and carbofuran to mosquito larvae. Environmental Toxicology and Chemistry $1991 ; 10: 1219-1227$.

Poli S, Sterlacchini S. Landslide Representation Strategies in Susceptibility Studies using Weights-ofEvidence Modeling Technique. Natural Resources Research 2007;16:121-134.

Preston S, Coad N, Townend J., Killham K, Paton GI. Biosensing the acute toxicity of metal interactions: Are they additive, synergistic, or antagonistic? Environmental Toxicology and Chemistry 2000;19:775-780.

ProUCL. Statistical Software ProUCL 4.00.05 for Environmental Applications for Data Sets with and withouth Nondetect Observations. US EPA; 2012. http://www.epa.gov/osp/hstl/tsc/software.htm. Accessed 4 March 2013.

RAIS. The Risk Assessment Information System; 2012. http://rais.ornl.gov/. Accessed 19 Jun 2012.

Ren D, Fu R, Leslie LM, Dickinson RE. Predicting Storm-triggered Landslides. Bulletin of the American Meteorological Society 2011;92:129-139.

Roslee R, Jamaluddin TA, Talip MA. Intergration of GIS using GEOSTAtistical INterpolations techniques (Kriging) (GEOSTAINT-K) in deterministic models for landslide susceptibilitly 
analysis (LSA) at Kota Kinabalu, Sabah, Malaysia. Journal of Geography and Geology 2012;4:1832.

SGI. The Göta River Commission: The final report. Swedish Geotechnical Institute; 2011. Available at $\quad$ http://www.swedgeo.se/templates/SGIStandardPage__2730.aspx?epslanguage=EN. . Accessed 18 Oct 2012.

SWECO VIAK. Tidermans utfyllnadsområde, huvudstudie. Del 2, åtgärdsutredning. (In Swedish), Sweco Viak; 2007.

Geertsema M, Highland LM, Vaugois L. Environmental impact of landslides. In K. Sassa, P. Canuti (eds.), Landslides - disaster risk reduction. Springer-Verlag Berlin Heidelberg 2009;585-604.

Serveiss V, Ohlson D. Using Ecological Risk Assessment Principles in a Source Water Protection Assessment. Human and Ecological Risk Assessment: An International Journal 2007;13:402-417.

Sterlacchini S, Frigerio S, Giacommeli P, Brambailla M. Landslide risk analysis: a multi-disciplinary methodological approach. Natural Hazards and Earth System Science 2007;7:657-675.

Sturve J, Balk L, Adolfsson-Erici M, Lindström P, Holmqvist I, Parkkinen J, Albertsson E, Carney Almroth B, Förling L. Effects of an oil spill in Göteborg harbour, Sweden assessed by biomarkers in eelpout (Zoarces viviparus). Marine Environmental Research2006;62:401.

Sturve J, Berglund Å, Balk L, Broeg K, Böhmert B, Massey S. Effects of dredging in Göteborg harbor, sweden, assessed by biomarkers in eelpout (zoarces viviparus). Environmental Toxicology and Chemistry 2005;24:1951-1961.

Sunderland EM, Amirbahman A, Burgess NM, Dalziel J, Harding G, Jones SH, Kamai E, Karagas MR, Shi X, Chen CY. Mercury sources and fate in the Gulf of Maine. Environmental Research 2012; 119: 27-41. 
Suter GW, Rodier DJ, Schwenk S, Troyer ME, Tyler PL, Urban DJ, Wellman MC, Wharton S. The U.S. Environmental Protection Agency's Generic Ecological Assessment Endpoints. Human and Ecological Risk Assessment: An International Journal 2004;10:967-981.

The UK Environment Agency. Environmental Quality Standards. http://www.environmentagency.gov.uk/research/planning/40295.aspx. Accessed 29 Jan 2013.

Thoft-Christensen P, Baker MJ. Structural reliability theory and its applications. Springer-Verlag, Berlin, New York; 1982.

US EPA. Ecological Risk Assessment, http://www.epa.gov/superfund/programs/nrd/era.htm. Accessed Oct. 172012.

US EPA. Data quality assessment: Statistical methods for data practitioners. EPA QA/G-9S. EA/240/B-06/003. Office of Environmental Information, US EPA, Washington DC; 2006 http://wwww.epa.gov/quality/gs-docs/g9s-final.pdf. Accessed 7 March 2013.

Walker LR, Velázquez E, Shiels AB. Applying lessons from ecological succession to the restoration of landslides. Plant \& Soil 2009;324:157-168.

Waples RS, Beechie T, Pess GR. Evolutionary history, habitat disturbance regimes, and anthropongenic changes: What do these mean for resilience of pacific salmons? Ecology and society $2009 ; 14: 3$. 


\section{Appendix A: Analysis of Landslide Probability $\left(P_{L}\right)$}

The analysis is made in two steps. In the first step an analytical solution for the probability of a landslide is developed. This solution is based upon a traditional model for slope stability analysis, incorporating parameter uncertainty (Alén, 1996, 1998). In the second step, time aspects are considered. By specifying parameters with variability in time based upon annual outcomes the annual probability for a landslide is estimated. The probability for a longer time period is then obtained by modelling the slope as a series system with each year as a component. A concise description of the methodology is given below. A more detailed description is provided in Berggren et al. (2011).

\section{A.1 Basic model}

The basic model for analysing slope stability is an equilibrium between stabilising actions, $R$, and disturbing ones, $E$, for a potential sliding soil mass; see Fig. 3a. The traditional safety concept is the global factor of safety:

$$
F=\frac{R}{E}
$$

Thus, $F>1$ gives a stable state. Equation A.1 can be modified to (Alén, 1998; Janbu, 1954):

$$
F=N \frac{c}{P d}
$$

where $N$ is a unit less stability number accounting for the shape of the slope and slip surface, $c$ the average shear strength of the soil along the slip surface, and $P d$ an unbalanced stress between driving forces of the weight of the soil, external loading and resisting forces, e.g., external water pressure at the toe of the slope. Since $F$ is given as product/ratio a reasonable assumption is that $F$ belongs to a lognormal distribution. Furthermore, the formulation opens up for considering three different types of uncertainty, 1) uncertainty of geometry through the stability number, 2) uncertainty of material 
properties through the shear strength and 3) uncertainty of different action effects through the unbalanced stress. This separation in uncertainties is basically the same that applies for any structure in civil engineering (EN1990, 2002). For $F$ to be lognormal these three different variables also have to belong to lognormal distributions. The computation of the probability of land sliding $\left(P_{L}\right)$ is done by using Eq. A.2 rewritten as:

$\ln F=\ln N+\ln c-\ln P d$

The probability of land sliding $\left(P_{L}\right)$ is then calculated as:

$P_{L}=p(\ln F<0)=\Phi\left(\frac{0-\mu_{\ln F}}{\sigma_{\ln F}}\right) \approx \Phi\left(-\frac{\ln \mu_{F}}{V_{F}}\right)$

where $\mu$ denotes a mean value and $\Phi($ ) denotes a standardised normal probability distribution. This equally applies for a coefficient of variation of moderate size, say less than $25 \%$. Furthermore, the same approximation yields the total uncertainty in the safety factor given as the coefficient of variation from:

$V_{F}^{2}=V_{N}^{2}+V_{c}^{2}+V_{P d}^{2}$

where the three different sub-coefficients of variations are assessed from estimated uncertainties, see Table A.1 and A.2, by an algorithm given in Berggren et al. (2011). As an alternative to $P_{\mathrm{L}}$ a reliability index $\beta$ can be defined as (EN1990, 2002):

$\beta=-\Phi^{-1}\left(P_{L}\right)$ i.e., the reliability for a year is $R=\Phi(\beta)$

From Equation A.4 follows that the reliability index can be estimated as:

$\beta=\frac{\ln \mu_{F}}{V_{F}}$ 
The described computation follows a methodology known as FORM (First order reliability method), see Thoft-Christensen and Baker (1982). Apart from the reliability index, FORM also gives as a result the so-called sensitivity factors $\left(a_{i}\right)$ for the different input parameters, which serve as indicators of the parameter influence on the calculated probability of failure. The computation becomes particularly simple in this case with the actual formulation of the failure criteria, i.e. $\ln F<0$ :

$$
\alpha_{N}=-\frac{V_{N}}{V_{F}}, \alpha_{c}=-\frac{V_{c}}{V_{F}} \text {, and } \alpha_{P d}=\frac{V_{P d}}{V_{F}}
$$

and with the relationship between the sensitivity factors:

$$
\sum_{i} \alpha_{i}^{2}=1
$$

The sign of the factors in Eq. A.8 indicates whether the parameter describes a disturbing or stabilising effect.

\section{A.2 Time aspects}

The probability of a landslide varies with time. In risk assessment this has to be accounted for with regard to two different aspects (Berggren et al., 2011). The first aspect is a continuous monotonic change in the prerequisites for a landslide over time. This might be due to natural geomorphological processes, as stated above in the introduction, but also a result of the transition into an anthropogenic system, e.g., by river erosion from ship traffic. Such a monotonic change will normally result in an increasing probability of failure over time, which can be modelled by a corresponding monotonic change in the relevant input parameters. The other time aspect to consider is the natural variability of the input parameters with time. This variability will normally be, if not the cause of a landslide, at least the triggering factor. The time aspects are closely related to the type of uncertainty involved, i.e., the natural variability can be seen as a genuine uncertainty, whereas other uncertainties which are permanent is more related to lack of knowledge. These latter ones also include the monotonic changes. 
The starting point for treating time aspects is an annual probability of a landslide $\left(p_{\mathrm{L} 1}\right)$. The basic model given above serves this purpose, if uncertainties of triggering factors are based upon statistics for annual outcomes. Such an approach is convenient since statistics frequently is assembled on an annual base. For the two extreme cases with either pure natural variability or pure lack of knowledge, the failure probability for other time periods can then be found. The reliability index $\beta$ is defined as:

$\beta_{1}=-\Phi^{-1}\left(P_{L 1}\right)$ i.e. the reliability for one year is $R_{1}=\Phi\left(\beta_{1}\right)$

and the reliability index can be estimated as:

$\beta_{1}=-\frac{\ln F-\ln \mu_{F}}{V_{F}}$

For the case with only natural variability the landslide probability is independent between years. Thus for a reference time $T$ (years) we have the reliability:

$\Phi\left(\beta_{T}\right)=\Phi\left(\beta_{1}\right)^{T}$ or,

$P_{L T}=1-\Phi\left(\beta_{1}\right)^{T}$

whereas for the case with only lack of knowledge no change in probability takes place over time:

$\beta_{T}=\beta_{1}$ or,

$P_{L T}=P_{L 1}=1-\Phi\left(\beta_{1}\right)$

For a normal slope neither of the two extreme cases apply, which makes the computation more complex. Instead a mix of the two types of uncertainty has to be considered. The case can be treated if the slope is seen as a series system, where each year is a component in the system. The mixed uncertainty of the system is then modelled by the correlation $(\rho)$ between the years. For such a system 
with the components given by normal distributions, i.e., by $\ln F$, the system reliability $\left(\boldsymbol{R}_{T}\right)$ is given by Thoft-Christensen and Baker (1982):

$\boldsymbol{R}_{T}=\int_{-\infty}^{\infty} \Phi\left(\frac{\beta_{1}+\sqrt{\rho} \cdot x}{\sqrt{1-\rho}}\right)^{T} \cdot \varphi(x) d x$

$p_{T}=1-\mathbb{R}_{T}$ and,

$\beta_{T}=\Phi^{-1}\left(\mathbf{R}_{T}\right)$

Finally, for the general case with mixed uncertainties and monotonic changes an analytical solution is not easily obtained. Instead Monte Carlo simulation can be performed. The factor of safety for a single year $i$ can for this purpose be rewritten as:

$F_{i}=\eta_{\text {dep }_{i}} \cdot \eta_{\text {indep }_{i}} \cdot \mu_{F i}$

where $\eta_{\text {dep }, i}$ is a factor considering the uncertainty from lack of knowledge, whereas $\eta_{\text {indep }, i}$ is a similar factor for natural variability between years. Both those factors can then be assumed to be lognormal with actual mean equal to one (or log mean zero). The uncertainty is given by the coefficient of variations $V_{d e p, i}$ and $V_{\text {indep }, i}$, which are also approximately equal to the $\log$ deviation, c.f. Eq. A.4. The third factor is a deterministic one equal to the mean value of the factor of safety and the actual year. An iteration $j$ in the Monte Carlo simulation $j$ then gives:

$\eta_{d e p_{i, j}}=\exp \left(V_{d e p_{i}} \cdot \Phi^{-1}\left(p_{d e p_{j}}\right)\right.$ and

$\eta_{\text {indep }_{i, j}}=\exp \left(V_{\text {dep }_{i}} \cdot \Phi^{-1}\left(p_{\text {indep }} p_{i, j}\right)\right.$

i.e., the same simulated probability each year for the dependent factor, but a unique simulated probability any year for the independent factor.

Hence, the Monte Carlo simulation results in a value of the safety factor $F_{i, j}$ for each year $i$ and each iteration $j$. The minimum value for any of the years of a single iteration governs whether that iteration 
will cause a landslide. The probability for a landslide within an arbitrarily chosen time period $i$ is then obtained by summation of such outcomes over all iterations:

$$
P_{L_{i}}=\sum_{j=1}^{N_{s i n}} \frac{\mathrm{H}\left(1-\min \left(F_{i, j}\right)\right)}{N_{s i m}}
$$

where $\mathrm{H}($ ) is Heaviside's step function.

Monotonic changes in time are, as discussed above, modelled as monotonic changes of relevant input parameters. In general, any year can be modelled in this way. In the actual case it is the river erosion that is considered as monotonic. However, the description of this erosion over a long time is quite uncertain. Basically very few observations of the erosion exist and only for short time periods. To incorporate the uncertainty explicitly in the model might then overshadow other uncertainties. Hence, in the decision model this monotonic change is given as a scenario, see Fig. $3 b$ in the paper. The simplest way to do this is through a linear trend for the time period considered. The probability computed is then a conditional probability given the trend.

In summary, the methodology used implies that the first and last year for a time period are analysed with the basic model described above, see Table A.1 and A.2 for the parameter values. Uncertainties of embankment geometry and soil properties are given as parameter uncertainties, which are constant over time. Variability in low water level, which is here the triggering factor for a potential landslide, is chosen from annual statistics, and finally the monotonic change in geometry caused by erosion is given as a time scenario. 


\section{Appendix B: Sedimentation in a River in Connection with an Instantaneous Release of}

\section{Material at a Point}

\section{B.1 Theoretical Model}

Suspended sediment transport in a river is often modelled using the ADE, especially if the sediment is fine and settles at a low rate:

$\frac{\partial c}{\partial t}+U \frac{\partial c}{\partial x}=D \frac{\partial^{2} c}{\partial x^{2}}-\frac{w c}{h}$

where $c$ is the concentration (mass per unit volume), $U$ the mean velocity in the river, $D$ the dispersion coefficient, $w$ the settling velocity, and $h$ the water depth. The model describes how sediment is transported downstream with the mean velocity, at the same time being subject to dispersion and settling at the bottom (the last term on the right-hand-side acts as a sink for sediment). The solution to the above equation for the case of a release of a mass $M(\mathrm{~kg})$ instantaneously at $x=0$ and $t=0$ is:

$$
c(x, t)=\frac{M}{A \sqrt{4 \pi D t}} \exp \left(-\frac{(x-U t)^{2}}{4 D t}-\frac{w t}{h}\right)
$$

where $A$ is the cross-sectional area of the river.

The dispersion coefficient can be calculated with the formula by Kashefipour and Falconer (2002):

$$
D=\left(7.428+1.774 \times\left(\frac{W}{h}\right)^{0.620} \times\left(\frac{U_{x}}{U}\right)^{0.527}\right) \times h \times U \times\left(\frac{U}{U_{x}}\right)
$$

where $W$ is the river width and $U_{x}$ the shear velocity, computed as:

$U_{x}=\sqrt{\frac{\tau_{b}}{\rho}} \quad$ and $\quad \tau_{b}=\rho \times g \frac{n^{2}}{R^{\frac{1}{3}}} \times U^{2}$

where $\tau_{b}$ is the bottom shear stress, $\rho$ is the water density, $g$ the gravity, $n$ the Manning's roughness coefficient for channels and $R$ the hydraulic radius. 


\section{B.2 Sediment Deposition at the Bed}

The rate at which the sediment is deposited at the bed at a certain location is given by $w c B$ (unit $\mathrm{kg} / \mathrm{m} / \mathrm{s}$, that is, mass per unit time and length of river), where $B$ is the width of the river (assumed to have an approximately rectangular shape; $A=B h$ ). Over a specific time period $\left(t_{o}\right)$, the amount sediment deposited at the bed $\left(q_{B} ;\right.$ unit $\left.\mathrm{kg} / \mathrm{m}\right)$ is given by:

$q_{B}=\int_{0}^{t_{o}} w c B d t$

If the analytical expression for $c$ is entered in the integral, then:

$q_{B}=\frac{M w}{\sqrt{4 \pi D} h} \int_{0}^{t_{o}} \frac{1}{\sqrt{t}} \exp \left(-\frac{(x-U t)^{2}}{4 D t}-\frac{w t}{h}\right) d t$

This integral can be solved, after some manipulations, to yield:

$q_{B}=\frac{M w}{4 \sqrt{D} h a} \exp \left(\frac{x U}{2 D}\right)\left(\exp (2 a b) \operatorname{erf}\left(a \sqrt{t_{o}}+\frac{b}{\sqrt{t_{o}}}\right)+\exp (-2 a b) \operatorname{erf}\left(a \sqrt{t_{o}}-\frac{b}{\sqrt{t_{o}}}\right)-2 \sinh (2 a b)\right)$

where erf denotes the error function and:

$a=\sqrt{\frac{U^{2}}{4 D}+\frac{w}{h}}$

$b=\frac{|x|}{2 \sqrt{D}}$

If the total amount of sediment deposited during the event $\left(q_{B, t o t}\right)$ is of interest, implying $t_{o} \rightarrow \infty$, the above equation may be simplified to:

$q_{B, t o t}=\frac{M w}{2 \sqrt{D} h a} \exp \left(\frac{x U}{2 D}-2 a b\right)$ 
This equation gives the total amount of material deposited at $x$ (per unit length); however, often it may be more interesting to obtain the amount deposited along a certain river stretch, which is obtained by integration in space. For example, the total amount of material deposited between $x_{1}$ and $x_{2}$ is given by:

$Q_{B}=\int_{x_{1}}^{x_{2}} q_{B, t o t} d x=\int_{x_{1}}^{x_{2}} \frac{M w}{2 \sqrt{D} h a} \exp \left(\frac{x U}{2 D}-2 a b\right) d x$

Because the coefficient $b$ contains the absolute value of $x$, some care has to be taken in the integration.

Here the result is presented for the case when all material deposited upstream $\left(Q_{B U}\right)$ a certain location $\left(x_{o}\right)$ is of interest. Thus, letting $x_{1} \rightarrow-\infty$ and $x_{2}=x_{o}$, the result is:

$\frac{Q_{B U}}{M}=1-\frac{2 \lambda}{1+4 \lambda-\sqrt{1+4 \lambda}} \exp \left(-\frac{1}{2} \eta(\sqrt{1+4 \lambda}-1)\right)$

where it is assumed that $x_{o}>0$, and the following non-dimensional quantities were introduced:

$$
\begin{gathered}
\lambda=\frac{w D}{U^{2} h} \\
\eta=\frac{x_{o} U}{D}
\end{gathered}
$$

If the material passing a point $x_{o}\left(Q_{B D}\right)$ is of interest, it can be obtained as the difference between the total amounts of material released $(M)$ and $Q_{B U}$, i.e., $Q_{B D}=M-Q_{B U}$.

\section{B.3 Sample Calculation}

Figure B1 below shows a typical sample plot of the total amount of material deposited upstream a specific location in non-dimensional form. 


\section{Tables and Figures}

Table 1. Summary of the three impact zones and associated release and exposure mechanisms (for description of $\mathrm{A}-\mathrm{E}$, see the text).

\begin{tabular}{llll}
\hline Impact Zone & I) Near field & II) Along pathway & III) Far field acc. area \\
\hline Refers to the site for the & Refers to the river stretch & Refers to the river outflow \\
event and the landslide & from the site to the & into an estuary, bay or lake \\
& deposits in the river & accumulation area & \\
\hline $\begin{array}{l}\text { Exposure and release } \\
\text { mechanisms }\end{array}$ & A and E & B and C, possibly also E & D and F \\
\hline
\end{tabular}

Table 2. Failure criterion in respective impact zone defined from the environmental quality standards (EQS) used in the case study (see www.rais.ornl.gov) and the additional load with respect to annual load (background).

\begin{tabular}{|c|c|c|c|c|}
\hline Impact zone & $\mathbf{I}$ & II & & III \\
\hline & & $\mathbf{a}$ & b & \\
\hline Distance (x) & $x=0 m$ & $x=0 m$ & $x=8400 m$ & $x>8400 m$ \\
\hline EQS & CISQG & ANAWQC & EDWD & Load \\
\hline Failure $\mathbf{P b}$ & $\mu_{\text {sed }}>35 \mathrm{mg} / \mathrm{kg}$ & $\mu_{w}>0.065 \mathrm{mg} / \mathrm{l}$ & $c_{w}>0.01 \mathrm{mg} / \mathrm{l}$ & $\begin{array}{l}W>1,10 \text { or } 50 \% \times 1735 \\
\mathrm{~kg} / \mathrm{yr}\end{array}$ \\
\hline Failure $\mathrm{Hg}$ & $\mu_{\text {sed }}>0.17 \mathrm{mg} / \mathrm{kg}$ & $\mu_{w}>0.0014 \mathrm{mg} / \mathrm{l}$ & $c_{w}>0.001 \mathrm{mg} / \mathrm{l}$ & $W>1,10$ or $50 \% \times 8 \mathrm{~kg} / \mathrm{yr}$ \\
\hline
\end{tabular}


Table 3. Chosen probability distributions for the uncertainty parameters for impact zones I-III.

\begin{tabular}{|c|c|c|c|c|c|c|c|}
\hline Parameter & & Unit & Distribution & Mode & Min & Max & Comments \\
\hline Landslide area & $A_{L}$ & $\mathrm{M}^{2}$ & Triangular & 10000 & 9000 & 11000 & $\begin{array}{l}\text { Measured on landslide risk analysis maps and refers to } \\
\text { uncertainty in the readings. }\end{array}$ \\
\hline Soil density & $\rho$ & $\mathrm{kg} / \mathrm{m}^{3}$ & Triangular & 1800 & 1700 & 1900 & Soil density of the contaminated soil. \\
\hline Landslide length along riverbank & $L_{L}$ & $\mathrm{~m}$ & Triangular & 300 & 290 & 310 & $\begin{array}{l}\text { Measured on landslide risk analysis maps and refers to } \\
\text { uncertainty in the readings. }\end{array}$ \\
\hline Soil depth (contaminated soil depth) & $d$ & $\mathrm{~m}$ & Uniform & - & 2.2 & 2.3 & $\begin{array}{l}\text { Estimated mean depth of soil contamination (filling material), } \\
\text { based on results reported in Sweco Viak, } 2007 \text { (consultant } \\
\text { report). }\end{array}$ \\
\hline River cross section area at the site & $A_{E}$ & $\mathrm{~m}^{2}$ & Uniform & - & 510 & 723 & Based on two cross sections at the site. \\
\hline Parameter & & Unit & Distribution & Mean & Std. Dev. & & Comments \\
\hline Average river cross section area & $A$ & $\mathrm{~m}^{2}$ & Normal & 614 & 69.03 & & Based on 10 cross sections. \\
\hline Average river water depth & $h$ & $\mathrm{~m}$ & Normal & 5.7 & 0.67 & & Based on 10 cross sections. \\
\hline Wetted perimeter & $P$ & $\mathrm{~m}$ & Normal & 148.5 & 21.18 & & Based on 10 cross sections. \\
\hline River width & $B$ & $\mathrm{~m}$ & Normal & 140.8 & 21.65 & & Based on 10 cross sections. \\
\hline Mean river flow & $Q$ & $\mathrm{~m}^{3} / \mathrm{s}$ & Lognormal & 161.20 & 28.57 & & $\begin{array}{l}\text { Based on daily mean, year 2002-2009. It is not possible to } \\
\text { tell whether the river flow will be low, high or at mean level }\end{array}$ \\
\hline
\end{tabular}


during the landslide. High flow yields increased velocity that has impact on erosion; however, a high flow (high water level) functions as a resisting force on the river slope. Low flow decreases the resisting forces and combined with high pore water pressure in the soil, the driving forces will be strong. A mean flow is also possible, depending on what triggers the slide (vessel induced erosion, additional loading from constructions etc.).

\begin{tabular}{|c|c|c|c|c|c|c|c|}
\hline Parameter & & Unit & Distribution & Mean & $\begin{array}{l}95 \% \\
\text { percentile. }\end{array}$ & Location & Comments \\
\hline Mean concentration of $\mathrm{Pb}$ in soil & $\mu_{\text {soil, } P b}$ & $\mathrm{mg} / \mathrm{kg}$ ds & Lognormal & 6580 & 17710 & 771 & $\begin{array}{l}\text { The distribution of the mean concentration was assumed to } \\
\text { be lognormal, defined as: mean (the maximum likelihood } \\
\text { estimate of the mean assuming a lognormal distribution), the } \\
95^{\text {th }} \text { percentile (the UCLM95 value calculated with the } \\
\text { Chebyshev method as implemented in ProUCL } 4.0 \text { (ProUCL, } \\
\text { 2012) assuming a lognormal distribution), and the location } \\
\text { which was assumed to be equal to the median of the } \\
\text { sample. Summary statistics of the Pb sample: } \mathrm{n}=37 \text {, mean } \\
=3026 \text {, median }=771, \mathrm{SD}=5623 \text {. }\end{array}$ \\
\hline Mean concentration of $\mathrm{Hg}$ in soil & $\mu_{\text {soil, }, H g}$ & $\mathrm{mg} / \mathrm{kg} \mathrm{ds}$ & Lognormal & 39.21 & 105.8 & 4.0 & $\begin{array}{l}\text { For explanation, see above. Summary statistics of the } \mathrm{Hg} \\
\text { sample: } \mathrm{n}=36 \text {, mean }=17.59 \text {, median }=4.00, \mathrm{SD}=44.96 \text {. }\end{array}$ \\
\hline
\end{tabular}




\begin{tabular}{|c|c|c|c|c|c|c|}
\hline Parameter & & Unit & Distribution & $1 \%$ percentile & 99\% percentile & Comments \\
\hline Ratio landslide soil in suspension & $S$ & & Lognormal & 0.01 & 0.1 & Estimated and based on the Agnesberg landslide \\
\hline Settling velocity & $w$ & $\mathrm{~m} / \mathrm{s}$ & Lognormal & 0.0002 & 0.002 & Clay, fine silt (contaminants are bound to the fine particles). \\
\hline
\end{tabular}


Table 4. Resulting probabilities of failure for each case. The vertical bar denote the term "given" in probability theory (example: $P_{f, I} \mid L$ means the probability of failure in impact zone I given a landslide).

\begin{tabular}{|c|c|c|c|c|}
\hline \multirow{2}{*}{ Impact zone } & \multirow{2}{*}{\multicolumn{2}{|c|}{ Failure definition }} & \multicolumn{2}{|c|}{ Probability of failure } \\
\hline & & & & \\
\hline \multirow[t]{2}{*}{$T$} & $P_{f, l} \mid L$ & $P\left[\mu_{\text {sed }}>C I S Q G\right]$ & 1 & 1 \\
\hline & $P_{f, 1}$ & $P\left[\mu_{\text {sed }}>C I S Q G\right] \times P_{L}$ & 3.0 E -03 & $3.0 \mathrm{E}-03$ \\
\hline \multirow[t]{2}{*}{ II a } & $P_{t, I l a} \mid L$ & $P\left[\mu_{w}>A N A W Q C\right]$ & 1 & 1 \\
\hline & $P_{t, \| l a}$ & $P\left[\mu_{w}>A N A W Q C\right] \times P_{L}$ & 3.0 E -03 & $3.0 \mathrm{E}-03$ \\
\hline \multirow[t]{2}{*}{ II b } & $P_{t, \| l \mid} \mid L$ & $P\left[c_{w}>E D W D\right]$ & 0.654 & 0.095 \\
\hline & $P_{t, \| b}$ & $P\left[c_{m w}>E D W D\right] \times P_{n w} \times P_{L}$ & 1.4 E -03 & 0.21 E -03 \\
\hline \multirow[t]{6}{*}{ III } & $P_{t, I I I \mid} L$ & $P\left[W>1 \% W_{b g}\right]$ & 0.795 & 0.818 \\
\hline & $P_{f, I I I}$ & $P\left[W>1 \% W_{b g}\right] \times P_{L}$ & 2.4 E -03 & $2.5 \mathrm{E}-03$ \\
\hline & $P_{t, I I I} L$ & $P\left[W>10 \% W_{b g}\right]$ & 0.321 & 0.359 \\
\hline & $P_{t, I I I}$ & $P\left[W>10 \% W_{b g}\right] \times P_{L}$ & 0.96 E -03 & $1.1 \mathrm{E}-03$ \\
\hline & $P_{t, I I I)} L$ & $P\left[W>50 \% W_{b g}\right]$ & 0.087 & 0.101 \\
\hline & $P_{f, I I I}$ & $P\left[W>50 \% W_{b g}\right] \times P_{L}$ & 0.26 E -03 & 0.30 E -03 \\
\hline
\end{tabular}

Table 5. The results of the sensitivity analysis of the transport model simulations, where $\mu_{w}=$ mean concentration in the water, $c_{w}=$ concentration in the water and $W$ is the additional load.

\begin{tabular}{llll}
\hline Criteria & Most influential parameters & $\mathbf{P b}$ & $\mathbf{H g}$ \\
\hline$\mu_{w}$ & Mean concentration in soil $\left(\mu_{\text {soil }}\right)$ & $65 \%$ & $68 \%$ \\
& Proportion in suspension $(S)$ & $33 \%$ & $31 \%$ \\
\hline \multirow{2}{*}{$c_{w}$} & Settling velocity $(w)$ & $-54 \%$ & $-53 \%$ \\
& Mean concentration in soil $\left(\mu_{\text {soil }}\right)$ & $25 \%$ & $27 \%$ \\
\hline
\end{tabular}




\begin{tabular}{llll}
\hline & Proportion in suspension $(S)$ & $9 \%$ & $8 \%$ \\
& & & \\
\hline & Settling velocity $(w)$ & $-560 \%$ & $-55 \%$ \\
$W(1 \%, 10 \%, 50 \%)$ & Mean concentration in soil $\left(\mu_{\text {soil }}\right)$ & $24 \%$ & $26 \%$ \\
& Proportion in suspension $(S)$ & $8 \%$ & $8 \%$ \\
\hline
\end{tabular}


Table A1. Slope stability analysis: probability distributions for uncertain parameters.

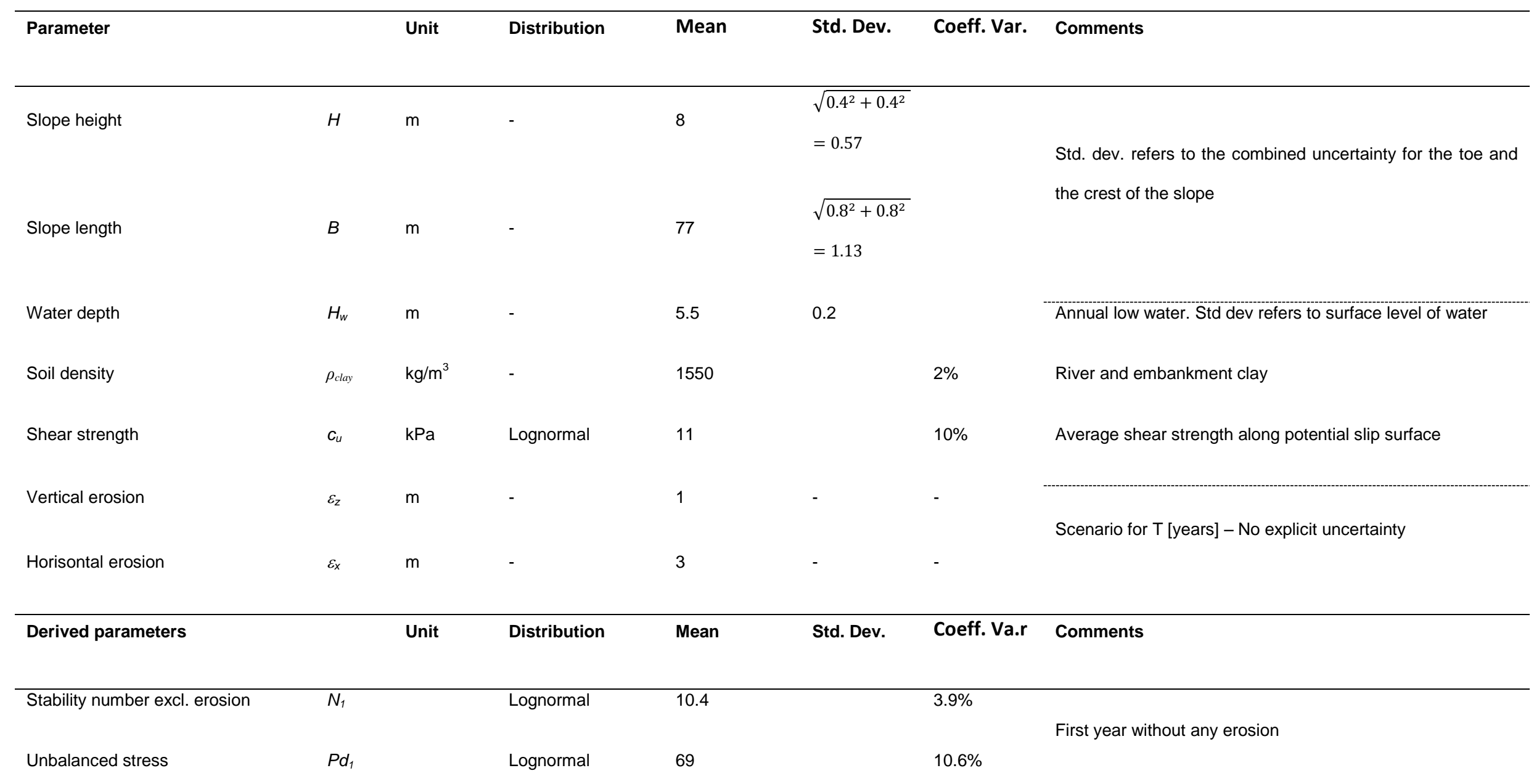


Factor of safety

Stability number incl. erosion

$P d_{T}$

$F_{T}$

Factor of safety
Lognornal

Lognormal

Lognormal

71.8

Lognormal

1.50
$5.1 \%$

$3.5 \%$

$10.3 \% \quad$ After T [years] of erosion]

$14.7 \%$ 
Table A2. Result of probabilistic slope stability analysis: analytical solution for first and last $\left(100^{\text {th }}\right)$ year

\begin{tabular}{|c|c|c|c|c|c|}
\hline \multirow{2}{*}{$\begin{array}{l}\text { Parameter } \\
\text { Reliability index }\end{array}$} & \multicolumn{2}{|c|}{ First year without any erosion } & \multicolumn{2}{|c|}{ Last year after T [years] of erosion] } & \multirow[t]{2}{*}{ Comments } \\
\hline & $B_{1}$ & 3.4 & $B_{T}$ & 2.6 & \\
\hline Sensitivity factor of independency & $\alpha_{\text {indep } 1}$ & 0.192 & $\alpha_{\text {indep } T}$ & 0.189 & Reflects uncertainty of low water level \\
\hline Sensitivity factor of dependency & $\alpha_{d e p 1}$ & 0.981 & $\alpha_{d e p T}$ & 0.982 & Reflects uncertainty of soil properties and geometry \\
\hline Probability of landslide & $P_{L 1}$ & $3.9 \times 10^{-4}$ & $P_{L T}$ & $4.2 \times 10^{-3}$ & Annual probability \\
\hline
\end{tabular}


Figure 1. Illustration of the impact zones I - III. The upward pointing arrows illustrate the release of contaminants from the runout deposit, the longitudinal arrows the transport of contaminants along the travel pathway, and the downward pointing arrows the sedimentation (settlement) of contaminants in accumulation areas.

Figure 2. Study site Göta Älv and Surte 2:38. The river Göta Älv runs from the Lake Vänern to the harbour of Gothenburg. Case site Surte 2:38 and the water intake are marked on the map.

Figure 3a. Schematic model for slope stability analysis. $H_{w}=$ water depth, $B=$ horizontal slope length, and $H=$ vertical slope hight.

Figure 3b. Schematic model for erosion in river. $\varepsilon_{z}=$ bottom erosion, $\varepsilon_{z}=$ bank erosion .

Figure 4. Landslide probability for Surte $2: 38$ as a function of a chosen reference time, where $\mathrm{P}_{\mathrm{L}}$ in the $\mathrm{y}$-axis is the landslide probability within a reference time $\mathrm{T}$ given in years. In the time considerations are on-going river erosion and varying water levels in the river due to the flow in the river and the sea level incorporated. The solid line shows the case with on-going erosion $\left(P_{L}=0.3 \%\right.$ for a time period of 50 years $)$ and the dashed line shows the case with no erosion $\left(P_{L}=0.15 \%\right.$ for a time period of 50 years).

Figure B1. Sample plot in non-dimensional form of the total amount of material deposited upstream a specific location. 
